\title{
Gene structural analysis and functional prediction of Chi protein produced by the bacterium Stenotrophomonas maltophilia
}

\author{
C.G. Oropeza-Flores, D. Galvez-Lopez, A. Vázquez-Ovando, \\ M. Salvador-Figueroa and R. Rosas-Quijano \\ Instituto de Biociencias. Universidad Autónoma de Chiapas. Tapachula, \\ Chiapas, México
}

Corresponding author: R. Rosas-Quijano

E-mail: raymundo.rosas@unach.mx

Genet. Mol. Res. 20 (1): gmr18689

Received July 24, 2020

Accepted December 21, 2020

Published February 28, 2021

DOI http://dx.doi.org/10.4238/gmr18689

\begin{abstract}
Molecular characterization of genes is a tool used to understand gene function. Chitin is the most abundant nitrogenous organic compound in nature; it is basically inert, but it can be transformed by the action of chitinases to several derivatives, which are of great interest in various areas of industry. These enzymes are widely distributed in many organisms and can be potentially used in genetic engineering to add characteristics that increase its activity. We examined 10 chitenase genes from 10 different strains of Stenotrophomonas maltophilia native to Chiapas, Mexico that have different enzymatic activities. After sequencing of the gene, a bioinformatic analysis was performed, which revealed an average length of $2100 \mathrm{bp}$ and $64.7 \% \mathrm{G}+\mathrm{C}$ content of the genes. The open reading frame consists of 699 amino acids, which corresponds to an average molecular mass of $72.4 \mathrm{kDa}$, and an isoelectric point of 6.66 . The genes exhibited between 99.3 and 100\% identity. Additionally, the 3D structure of the chitinolytic enzyme was predicted using the structure of a chitinase from Streptomyces thermoviolaceus as a template. Results suggested that the chitinase of S. maltophilia contains four characteristic domains of these enzymes, the Chia1_BD, Big_3_5, type III fibronectin (FN3), and GH18 domains.
\end{abstract}


This study provides basic knowledge for enzyme design using genetic engineering.

Key words: Sequences; Protein prediction; Chitin domains; Phylogeny; Chitinase

\section{INTRODUCTION}

The characterization of genes allows determination of their structure, size, function, and expression pattern. Through this process, it is possible to identify the order of each nucleotide in the coding region, including the elements that make up the open reading frame $(\mathrm{ORF})$, the regulatory zones, and the complete expression system of the gene (Perera et al., 2000). Other important aspects that complement the characterization of gene sequences include the determination of the motifs and domains that make up the coding protein (Beker and Sali, 2001).

Chitinases are glycosyl hydrolase enzymes that catalyze the hydrolysis of the $\beta$ 1-4 glycosidic bonds of chitin (Hamid et al., 2013). They are produced by a wide range of organisms, including bacteria, fungi, plants, some viruses, and insects (Yuli et al., 2004; Rathore and Gupta, 2015). Chitinases are used to hydrolyze chitin to low molecular weight chito-oligosaccharides (Shiro et al., 1996) or to the N-acetyl-D-glucosamine monomer.

Chitinase-producing bacteria have been isolated from various environments, including soil, hot springs, shellfish waste, and sewage (Shiro et al., 1996). Chitinases have been divided into two groups, endo-chitinases and exochitinases. According to their amino acid sequence, they can be classified into two families: GH18 and GH19. The chitinases of the two families do not share similarities in the sequence of amino acids and have different 3D structures and molecular mechanisms (Metcalfe et al., 2002). Due to the ubiquity of chitin, a diverse variety of chitinases have been isolated from different microorganisms including Streptomyces (Blaak and Schrempf, 1995) Alteromonas (Tsujibo et al., 1993) Escherichia (West and Colwell, 1984), Aeromonas (Sitrit and Vorgias, 1995), Bacillus (Zhong et al., 2015), and others, as well as from plants such as soy (Glycine max) (Chang et al., 2014) and fungi such as Trichoderma harzianum (Viterbo et al., 2001).

The sizes of the genes coding for chitinases (Chi) vary by species. In Pseudomonas, the $P s C h i C$ gene is 1443 bp (Zhong et al., 2015). In Bacillus thuringiensis, the ChiA74 gene is 2031 bp (Barboza et al., 2003), and the Chi gene of Stenotrophomonas maltophilia is 2800 bp (Kobayashi et al., 2002). The EuCHIT2 gene of Eucommia ulmoides is 1218 bp in length (Dong et al., 2017).

Stenotrophomonas maltophilia is a bacterium with diverse biotechnological applications given its use in the biotransformation and bioremediation of residues (Suckstorff and Berg, 2003; Gren et al., 2010) and as a biocontrol agent (Tan and Yin, 2015). In addition to producing chitinases, S. maltophilia possesses genes encoding other enzymes that are related to biodegradation. Its genome encodes xylosidase and xylanase enzymes, among others (Kok et al., 2015).

Stenotrophomonas maltophilia produces large quantities of chitinases when induced by chitin (Kok et al., 2015). Even with all of the information that has been generated regarding chitinases in S. maltophilia, the genetic determinants that encode these enzymes in this species have been poorly studied. Recently, the isolation and morphogenetic 
characterization of 10 strains of $S$. maltophilia of marine origin from Chiapas, Mexico (B1B10) that degrade chitin were reported, and these 10 strains have different capacities to hydrolyze chitin, with values ranging from 2000 to $8000 \mathrm{U} / \mathrm{mg}$ (Salas-Ovilla et al., 2019).

The characterization of Chi genes present in strains B1-B10 could contribute to future research in genetic engineering and could also help explain the differences found in enzymatic activity for each isolate, and thus allow development of value-added products. Consequently, our objective was to characterize the primary structure of genes encoding chitinolytic enzymes and predict the protein domains of these 10 strains of $S$. maltophilia.

\section{MATERIAL AND METHODS}

\section{Biological material}

Ten strains of S. maltophilia (B1, B2, B3, B4, B5, B6, B7, B8, B9, and B10) from the collection of strains from the Institute of Bioscience of the Autonomous University of Chiapas were used. These were previously reported by Salas-Ovilla et al. (2019).

\section{Design of oligonucleotides for Chi genes}

The design of the oligonucleotides used in this study was firstly performed by multiple alignment that displayed the analysis of the 10 first sequences of genes encoding specific chitinases of S. maltophilia (NCBI, 2017) using the program MEGA 7 (Kumar et al., 2016). The alignment consensus sequence of the gene from the start (ATG codon) to the end (stop codon) was considered, including the size and the Tm (Table 1).

Table 1. Oligonucleotides designed to amplify the Chi gene of Stenotrophomonas maltophilia.

\begin{tabular}{lllll}
\hline Name & Oligonucleotide & Number of bases & Tm $\left({ }^{\circ} \mathbf{C}\right)$ & Expected amplicon (bp) \\
\hline Forward & ATGTACGACCCGATTGTGC & 19 & 58 & 2100 \\
Reverse & AATGAAGTCCGGTAGTGAC & 19 & 52 & \\
\hline${ }^{\circ}$ C: degree centigrade; bp: bases pairs & &
\end{tabular}

\section{Extraction of genomic DNA}

The extraction of genomic DNA from the 10 selected strains of $S$. maltophilia was performed using the modified method of De et al. (2010), which consisted of recovering the cells of the strains grown in colloidal chitin agar medium by centrifugation (Eppendorf ${ }^{\circledR}$ $5430 \mathrm{R})$ at $5000 \mathrm{rpm}$ for $5 \mathrm{~min}$. Cell pellets were recovered and washed with $800 \mu \mathrm{L}$ of NaCl-EDTA ([30 mM NaCl, $2 \mathrm{mM}$ EDTA] pH 8.0). The bacterial pellet was washed and resuspended in $100 \mu \mathrm{L}$ of lysozyme $(50 \mathrm{mg} / \mathrm{mL}$; Promega); the mixture was incubated at $37^{\circ} \mathrm{C}$ for 1 hour with $4 \mu \mathrm{L}$ of RNAse $(10 \mu \mathrm{g} / \mathrm{mL}$; Promega). After incubation, glass beads $(0.42 \mathrm{~mm})$ were added. Then, $500 \mu \mathrm{L}$ of NaCl-EDTA $(30 \mathrm{mM})$ and $50 \mu \mathrm{L}$ of SDS $(10 \%$; Sigma-Aldrich) were added to the volume of the mixture, followed by the addition of $10 \mu \mathrm{L}$ of proteinase $\mathrm{K}(25 \mathrm{mg} / \mathrm{ml}$; Bio-Rad). The total volume $(700 \mu \mathrm{L})$ was mixed vigorously and incubated at $55{ }^{\circ} \mathrm{C}$ for one hour. After incubation, $700 \mu \mathrm{L}$ of Sigma-Aldrich-brand saturated phenol was added with $(1 \mathrm{M})$ Tris- $\mathrm{HCl}$ at $\mathrm{pH}$ 8. The resulting mixture was centrifuged at 
$10,000 \mathrm{rpm}$ at $22^{\circ} \mathrm{C}$ for $10 \mathrm{~min}$, and the aqueous phase was separated. The step was repeated with a phenol-chloroform aliquot $(1: 1)$. The mixture was centrifuged at 10,000 rpm for $10 \mathrm{~min}$, and the aqueous phase was recovered and transferred to a new tube. Then, 600 $\mu \mathrm{L}$ of Sigma-Aldrich isopropanol was added to the supernatant in the presence of $70 \mu \mathrm{L}$ of sodium acetate (3 M, pH 5.2). The supernatant was discarded, and $500 \mu \mathrm{L}$ of $70 \%$ ethanol was added to the pellet, which was centrifuged at $10,000 \mathrm{rpm}$ for $2 \mathrm{~min}$. The ethanol was discarded, and the tube was placed in a concentrator to dry the residual ethanol. The final pellet was dissolved in $50 \mu \mathrm{L}$ of Tris-EDTA $(10: 1 \mathrm{mM})$ at $\mathrm{pH}$ 8.0. The DNA concentration was quantified using a spectrophotometer (GENWAY ${ }^{\circledR}$, Genova Nano Model), and the DNA quality was verified by electrophoresis at $80 \mathrm{~V}$ for $30 \mathrm{~min}$ on a $1 \%$ agarose gel. The gel electrophoresis results were visualized using a photodocumenter (Bio-Rad model Gel Doc $\mathrm{XR}+$ ) with the program Image Lab from Bio-Rad. The sample was stored at $-20^{\circ} \mathrm{C}$ until further use.

\section{Amplification}

Amplification of the gene of interest was performed in a thermocycler (Applied Biosystems ${ }^{B}$ Veriti model) with a protocol consisting of an initial stage of heating at $94^{\circ} \mathrm{C}$ for $2 \mathrm{~min}$, followed by 30 cycles of denaturation at $94^{\circ} \mathrm{C}$ for $30 \mathrm{~s}, 55^{\circ} \mathrm{C}$ for $30 \mathrm{~s}$, and $72^{\circ} \mathrm{C}$ for $2 \mathrm{~min}$ and a final stage of $72^{\circ} \mathrm{C}$ for $7 \mathrm{~min}$. The reaction mixture consisted of $5 \mu \mathrm{L}$ of $5 \mathrm{x}$ buffer, $1 \mu \mathrm{L}$ of $\mathrm{MgCl}_{2}(50 \mathrm{mM}), 1 \mu \mathrm{L}$ each of the forward and reverse oligonucleotides (both $10 \mu \mathrm{M}), 1 \mu \mathrm{L}$ of dNTPs $\left(2.5 \mathrm{mM}\right.$ each), $14.75 \mu \mathrm{L}$ of $\mathrm{H}_{2} \mathrm{O}$ MilliQ, $0.25 \mu \mathrm{L}$ of Taq DNA polymerase $(5 \mathrm{U} / \mu \mathrm{L})$, and $1 \mu \mathrm{L}$ of DNA template B1 $(40.71 \mu \mathrm{g} / \mathrm{ml}), \mathrm{B} 2(25.31$ $\mu \mathrm{g} / \mathrm{mL})$, B3 $(24.44 \mu \mathrm{g} / \mathrm{mL})$, B4 $(13.48 \mu \mathrm{g} / \mathrm{mL})$, B5 $(11.08 \mu \mathrm{g} / \mathrm{mL})$, B6 $(9.909 \mu \mathrm{g} / \mathrm{mL})$, B7 $(113.1 \mu \mathrm{g} / \mathrm{mL})$, B8 $(201.1 \mu \mathrm{g} / \mathrm{mL})$, B9 $(55.58 \mu \mathrm{g} / \mathrm{mL})$, or B10 $(29.43 \mu \mathrm{g} / \mathrm{mL})$. The amplification products were visualized by electrophoresis $(80 \mathrm{~V}$ for $30 \mathrm{~min})$ on a $1 \%$ agarose gel.

\section{Purification and sequencing of amplicons}

The amplicons were purified using an EZ1-10-Spin Column PCR products purification kit (Bio Basic), following the protocol of the manufacturer. The purified product was sent to the National Institute of Biotechnology of the National Autonomous University of Mexico for sequencing using the Sanger method (Sanger et al., 1977). Two sequences were performed for each sample, one using the forward oligonucleotide and another with the reverse oligonucleotide (Table 1).

\section{Bioinformatics analysis}

The sequences of the electropherograms were analyzed using the Bioedit program. For each of the genes, both sequences (forward and reverse) were assembled using the SeqMan suite from the DNASTAR (Lasergene ${ }^{\mathrm{TM}}$ ) program. Subsequently, BLASTx analysis (https://www.ncbi.nlm.nih.gov/) was performed to determine the identity of each sequence. The identities of the genes of each strain were obtained through the program Clustal Omega (https://www.ebi.ac.uk/Tools/msa/clustalo/). Bio-PHP software (http://www.biophp.org/) was used to calculate the $\mathrm{G}+\mathrm{C}$ percentage. The ORF Finder 
program was used to determine the coding region https://www.ncbi.nlm.nih.gov/orffinder/). This coding region was translated to amino acid sequences and were used for subsequent analysis.

Phylogeny of chitinolytic genes and amino acids of S. maltophilia: Two phylogenetic trees (bootstrapping with 1000 replicates) were generated, one at the nucleotide level and another at the amino acid level, using the program MEGA 7. For nucleotide tree, it were included three sequences of $S$. maltophilia deposited on the gene bank (NCBI) as reference sequences: CP029759.1:c606270-604171, CP025780.1:265748-267847, CP050452.1:638709640808. For amino acid tree, the $S$. maltophilia reference sequences included were: WP_164230468.1, WP_164263773.1, and QNA94742.1. Also, three different species were included in each tree as external groups: for nucleotide, Arabidopsis thaliana (AY054628.1:18983), Penicillium digitatum (XM_014678883.1), Autographa californica (KM609482.1:100756102408); for amino acids, Arabidopsis thaliana (BAB03157.1), Penicillium digitatum (XP_014534369.1), Autographa californica (AKN58976.1).

Predictive analysis of the chitinase enzyme of S. maltophilia: Protein domains were identified using the Conserved Domain Search Service (SD Search) program. The Protein Calculator V3.3 program (http://protcalc.sourceforge.net/cgi-bin/protcalc) was used to predict the molecular mass and the isoelectric point of the protein.

Hypothetical 3D modeling of the protein chitinase: Prediction of the 3D structure of the protein was performed with the PyMol 1.4.7 program. For this process, a chitinase from Streptomyces thermoviolaceus (GeneBank accession number: MF629669.1), which was deposited in the Protein Data Bank (PDB) (https://www.rcsb.org/), was used as a template, and three models were performed for this analysis.

\section{RESULTS}

The PCR-amplified products of the Chi genes of the strains used showed an amplicon of approximately $2000 \mathrm{bp}$ (Figure 1). The analysis of the sequence indicated a length of approximately $2100 \mathrm{bp}$, and the $\mathrm{G}+\mathrm{C}$ percentage was $67.4 \%$.

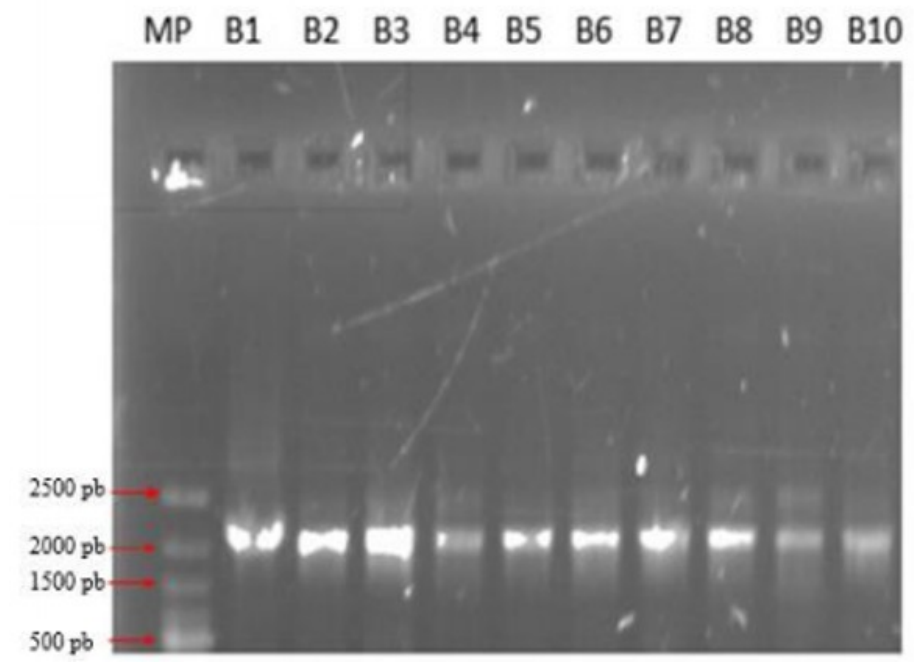

Figure 1. Amplicons of the chitinolytic genes obtained from strains B1-B10: Lane 1 (M) (molecular weight marker, O'GeneRuler ${ }^{\mathrm{TM}} 100$ bp Plus, Thermo Scientific ${ }^{\mathrm{TM}}$ ), lanes 2 to 11 (amplicons for each Stenotrophomonas maltophilia strain, B1 to B10). 
The comparative analysis (BLASTx) of the sequence of the 10 strains against the data bank (NCBI) showed that the identity value of these strains with $S$. maltophilia ranged between 98.57 and $99.71 \%$, with a coverage of $99 \%$.

\section{Phylogeny of the DNA sequences of $S$. maltophilia}

The cluster analysis of the sequences of the $10 \mathrm{Chi}$ genes of this study confirmed the similarity to the Chi genes of three strains of $S$. maltophilia reported in the gene bank (Figure 2); therefore, these genes are phylogenetically distinct from those of other species (Autographa californica, Penicillium chrysogenum, and Arabidopsis thaliana). The analyzed strains of this study were classified into two subgroups (I and II blue box), where strain B1 B7 and B8 are particularly distinct from the others, but most similar to those reported in the gene bank (CP029759.1:c606270-604171 Stenotrophomonas sp. pho chromosome); likewise, strains B2, B4, B5, B6, B9 and B10 formed another group, different from the other collection strains.

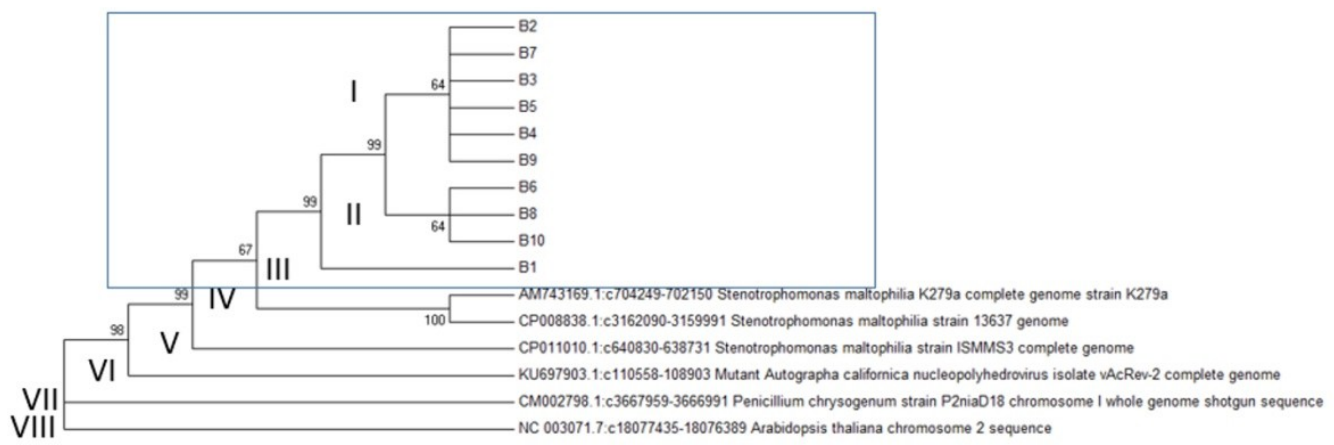

Figure 2. Phylogenetic tree of the nucleotide sequences of the chitinolytic genes. Stenotrophomonas maltophilia strains B1 to B10; reference strains of S. maltophilia: CP029759.1:c606270-604171, CP025780.1:265748-267847 and CP050452.1:638709-640808, accession numbers. And external group: Arabidopsis thaliana, (XM_014678883.1); Penicillium digitatum (XM_014678883.1) and Autographa californica (KM609482.1:100756-102408).

\section{Phylogeny of the amino acid sequences of $S$. maltophilia chitinases}

Cluster analysis of the amino acid sequences separated the strains of this study into three different groups (Figure 3): The first group included the strains B2, B4, and B10 (orange box), the second grouped the strains B3, B5, B6, B7, B8, and B9, (blue box); and the third the B1 strain. The B1 strain had similarity with the strains of $S$. maltophilia reported in the NCBI database, and this behavior was resembled to the nucleotide alignment. 


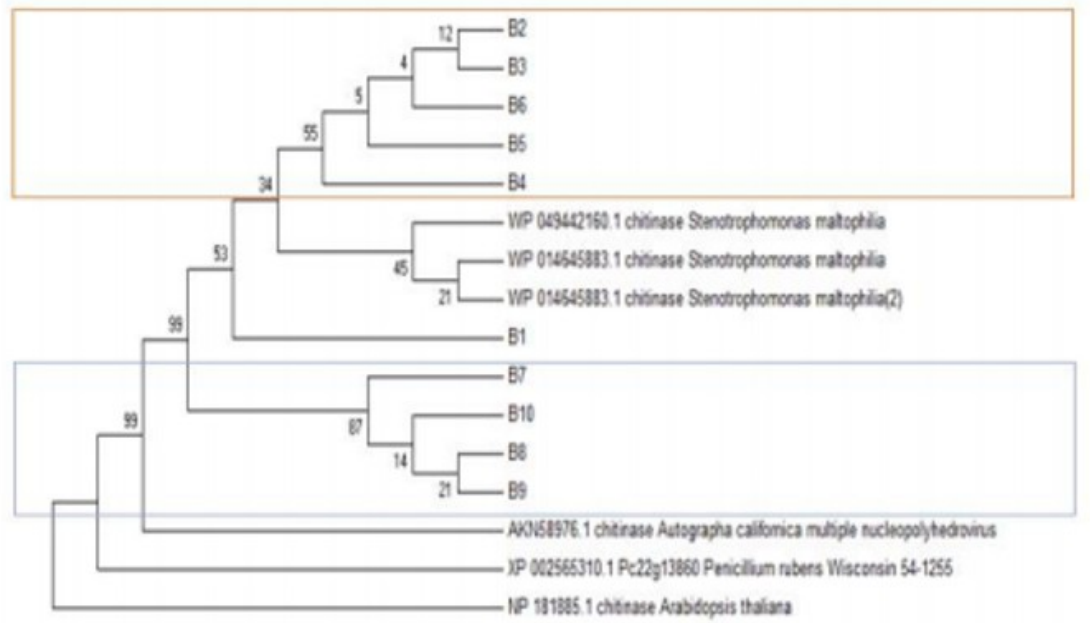

Figure 3. Phylogenetic tree of the deduced amino acid sequences. The strains Stenotrophomonas maltophilia (B1 to B10) of this study; the reference strains of S. maltophilia: WP 164230468.1, WP 164263773.1, QNA94742.1 accession number. And external group: Arabidopsis thatiana, (BAB03157.1); Penicillium digitatum (XP_014534369.1) and Autographa californica (AKN58976.1).

\section{Prediction of the primary structure of the chitinase enzyme of the 10 strains of S. maltophilia}

Prediction of the primary structure of the proteins of strains B1-B10 showed that the ORF consists, on average, of 699 amino acids (Figure 5), with a molecular mass of 72.9 $\mathrm{kDa}$ and an isoelectric point of 6.66. For all S. maltophilia strains B1-B10, the predictive analysis yielded that, the chitinase enzyme is composed of four characteristic domains of the chitinases of family 18 . Figure 4 is a representative chitinase of all strains that describes the chitinases domains of family 18. The chitin binding domain ChiA_BD is located between amino acids 49 and 88 . The Big 3_5 domain, located between amino acids 114 and 194, is composed of folds similar to those of immunoglobulins (IGs). The FN3 or type III fibronectin domain, located between amino acids 200 and 274, contains a flexible loop between two chains, which is characteristic of some domains present in both intracellular and extracellular proteins. A 17-amino acid motif was found in this domain. Finally, the G18-glycosyl hydrolase domain is located between amino acids 300 and 699, and the latter part contains an eight-strand beta/alpha barrel structure and a pronounced cleavage at the active site at the $\mathrm{C}$-terminus of the beta-barrel.

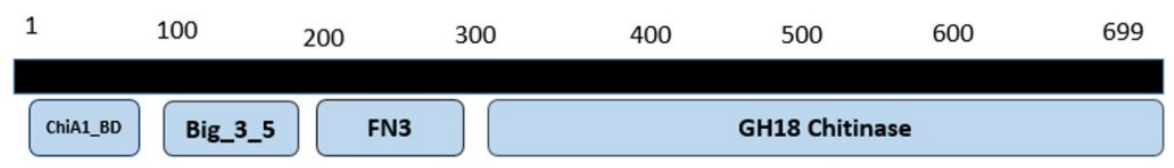

Figure 4. Domains present in chitinases of Stenotrophomonas maltophilia strains B1-B10 (amino acids 1 to 699). 


\section{D model of the hypothetical chitinase}

Hypothetical 3D modeling of the protein chitinase with the Pymol program, and the tertiary structure of the chitinase of strain B6 was constructed (Figure 5). The structural differences observed among the three tentative models were not significant. Figure 5 shows the tertiary structure modeling where the characteristic domains of family G18 of chitinases are evident: Figure 5A shows a TIM barrel structure, and the eight alpha helices numbered from 1 to 8, comprised in the structure; figure 5B shows the ChiA_BD domain; in figure 5C, the Big 3 5 domain; finally, in Figure 5D, the FN3 domain in the lower right. The structure had a high percentage of proline in the amino acid sequence.

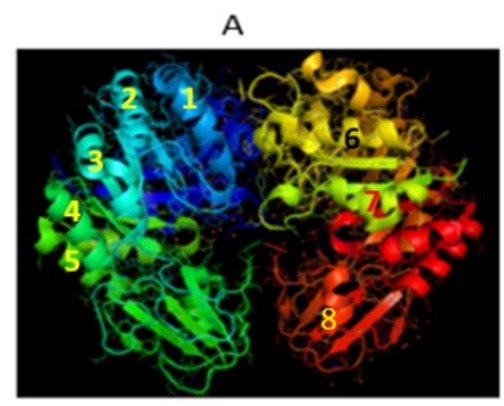

C

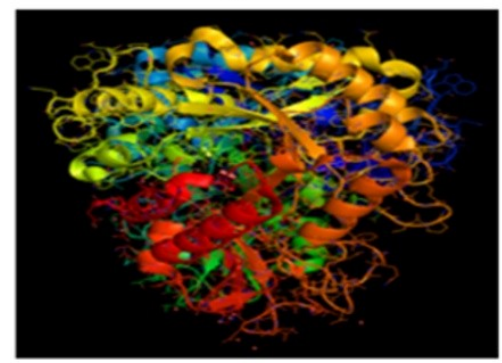

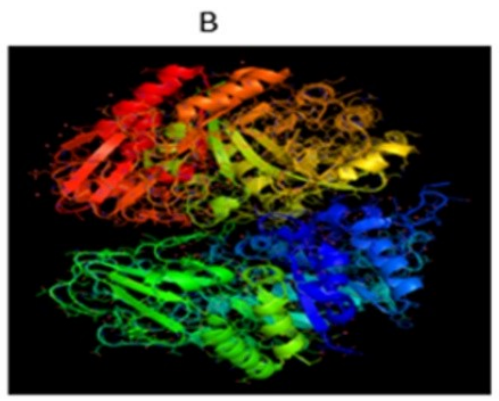

$\mathrm{D}$

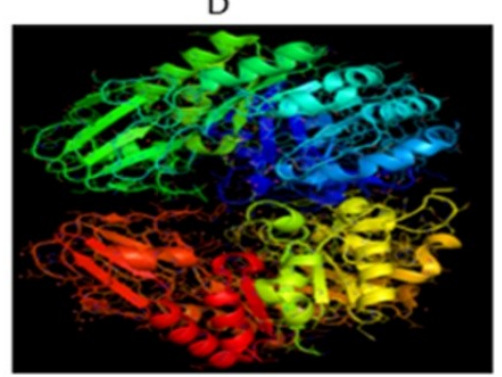

Figure 5. The 3D model of the sequence encoding to the chitinase of the B6 strain Stenotrophomonas maltophilia. A: TIM barrel structure that shows the eight alpha helices, numbered from 1 to 8 . B: ChiAl BD domain in blue. C: The Big_3_5 domain is shown in red. D: FN3 domain in the lower right is shown in yellow.

\section{DISCUSSION}

The amplicons found by sequencing $(2100 \mathrm{bp})$ confirmed that the $S m C h i$ chitinolytic gene of the B1-B10 strains of $S$. maltophilia used in this study presents high similarity in terms of the composition of the primary structure and size to the 33 strains of $S$. maltophilia reported in the NCBI databases, with homology ranging from 82.44 to $98.76 \%$. Additionally, Kobayashi et al. (2002) reported a SmChiA gene in the 2800 bp fragment for the same species, which had an ORF of $2100 \mathrm{bp}$ that is similar to the one found in this study. These findings demonstrate the low genetic variability of the SmChi gene within the same species, S. maltophilia, and that the variability of this gene is high between different species. For example, the PsChiC chitinolytic gene of Pseudomonas spp. has been reported 
to have a size of 1443 bp (Zhong et al., 2015) the ChiA74 gene of Bacillus thuringiensis has a size of 2031 bp (Barboza et al., 2003), while the SlChi gene of Serratia liquefaciens is $1691 \mathrm{bp}$. These findings are validated by the phylogenetic analysis shown in Figure 2, which shows the genetic differences between the sequences of genes of the same species and between different species.

The phylogenetic tree of the amino acid sequences of the SmChi gene also showed that among the strains examined in this study, the genetic difference is low, even when compared between the sequences of $S$. maltophilia strains in the database. However, strain $\mathrm{B} 1$ is different from the other strains because it is separated from the group and from those strains reported. Salas-Ovilla et al. (2019) reported a difference in chitinolytic activity between strains B1 and B10; however, such chitinolytic capacity has not been explained, even in the analyses characterizing the primary DNA structure and amino acid sequences of the strains used in this study. It is worth mentioning that the amino acid sequences of the strains of other species show large genetic differences for this gene. Some molecular studies have shown that chitinases are modular, that is, they share domains with other glycosyl hydrolase proteins from other species (Busby et al., 2012; Laribi et al., 2015; Oyeleye and Yahaya, 2018), but these proteins can differ according to their structural organization (Kobayashi et al., 2002); for example, the proteins can vary at the level of the positions of discrete domains or the catalytic domains, which could explain the possible differences in the chitinolytic capacity among strains B1-B10.

The analysis of chitinase for strains B1 to B10 showed similarity (ORF of 699 amino acids, molecular mass $72.9 \mathrm{KDa}$, isoelectric point of 6.66) to that reported by Kobayashi et al. (2002), who reported an ORF of 700 amino acids and a molecular mass of $72.4 \mathrm{KDa}$ for the chitinase of the SmChiA gene of S. maltophilia. This chitinase also showed similarity to chitinases of $B$. thuringiensis, which has isoelectric point values ranging from 6.48 to 6.64 (Honda et al., 2017). In the chitinase of strains B1 to B10, the catalytic domain belongs to the G18 family of glycosyl hydrolases and ranges from the amino acid tyrosine at position 302 to the tryptophan at position 679; this domain coincides with that reported by Kobayashi et al. (2002) for SmChiA chitinase, although they do not report the initial and terminal residues of the domain. This similarity at the catalytic site between the SmChi genes, up to this point, does not fully explain the differences in chitinolytic capacity among the strains; however, a crystallization study of this protein could yield the exact structure of the domains that compose it. It is noteworthy that within the structure of the protein of strains B1 to B10, the ChiA1_BD, Big_3_5, and FN3 domains are also present, similar to the chitinase SmChiA gene reported by Kobayashi et al. (2002), who also found specific chitinases of $S$. maltophilia reported in the NCBI database. These domains are not reported in the chitinases of strains of other species, with the exception of the GH18 domain; therefore, the domains ChiA1_BD, Big_3_5, and FN3 are exclusive to the chitinases of $S$. maltophilia.

In particular, the FN3 domain of chitinase in strains B1 to B10 is present in all glycosyl hydrolase enzymes of the G18 family and has been considered an evolutionary characteristic that has been structurally conserved over time (Bork and Doolittle, 1992); this domain is related to the thermodynamic stability of the protein (Shah et al., 2016). In addition, it contains aromatic residues that are responsible for binding to the substrate, thus improving the catalytic efficiency of the enzyme (Uchiyama et al., 2001). It is worth mentioning that for the chitinase of the strains examined in this study, only one FN3 domain 
was identified; however, other bacterial chitinases may contain up to two or more domains of this type, as in the case of Bacillus circulans (Vaaje et al., 2013). Finally, this domain in strains B1 to B10 contains a host cytokine motif of 17 amino acids (which is initiated by alanine and ends in asparagine), which, given its nature, allows the protein to exhibit an extra- and intracellular receptor capacity.

The protein modeling analysis suggested that the chitinase of the strains in this study is located within subcategory A of the GH18 family because it showed a pronounced structure in the active site, which is not characteristic of subcategories $\mathrm{B}$ and $\mathrm{C}$ ( $\mathrm{Li}$ and Greene, 2010). The GH18 domain includes a TIM barrel, which is considered the active site of chitinase, and its function is to hydrolyze the $\beta 1-4$ bonds present in the residues of $\mathrm{N}$ acetyl D-glucosamine ( $\mathrm{Li}$ and Greene, 2010). The TIM barrel of this template structure has a pronounced groove that favors binding to the substrate, a characteristic known to be present in the chitinases of the strains of this study. For its part, the structure of the protein selected as a matrix for modeling showed low homology with the known structures of other chitinolytic proteins deposited in the PDB, likely because these molecules are flexible and difficult to crystallize (Malecki et al., 2013). Nonetheless, the selected protein presented $50 \%$ homology with the structure of the predicted proteins coded by the genes examined this study, given the amount of proline observed. Within the analysis, it was not possible to determine all changes in the amino acids to observe the possible virtual changes in the structure constructed from the template structure. Therefore, the development of other studies is necessary, such as regulatory sequence analysis, expression analysis, protein crystallography, among others, in order to identify specific elements or parameters that allow the screening of chitinolytic enzymes with biotechnological potential. Finally, this study is the basis knowledge for future enzyme designs using genetic engineering in our laboratory.

\section{CONCLUSIONS}

Characterization of the primary structure of the genes encoding the chitinase enzyme of S. maltophilia strains B1-B10, and the prediction of the protein domains were performed. The DNA and amino acid sequences for all B1-B10 strains showed high similarity with $S$. maltophilia reported in data bank. The chitinase prediction analysis, identified four motifs (Big_3_5, FN3, GH18 and ChiA1_BD) characteristic of the hydrolases of family 18. A single FN3 motif was identified in the protein structure of the studied strains and a cytokine receptor within the domain FN3. The protein modeling analysis suggests that the chitinase of the strains in this study is located within subcategory A of the GH18 family. This study did not correlate the differences in enzymatic activity between all strains, nevertheless is the basis for future enzyme analysis and designs using genetic engineering, in order to explore the chitinolytic biotechnological potential.

\section{ACKNOWLEDGMENTS}

We thank the Secretaria de Educacion Publica of Mexico for financing the project SEP-PRODEP DSA/103.5/16/14474, granted to R. Rosas-Quijano. 


\title{
CONFLICTS OF INTEREST
}

\author{
The authors declare no conflict of interest.
}

\section{REFERENCES}

Barboza-Corona JE, Nieto-Mazzocco E, Velázquez-Robledo R, Salcedo-Hernandez R, et al. (2003). Cloning, sequencing, and expression of the chitinase gene chiA74 from Bacillus thuringiensis. Appl Environ Microbiol. 69(2): 1023-1029. DOI: 10.1128/aem.69.2.1023-1029.2003.

Baker D and Sali A (2001). Protein structure prediction and structural genomics. Science. 294(5540): 93-96. DOI: $10.1126 /$ science. 1065659 .

Blaak H and Schrempf H (1995). Binding and substrate specificities of a Streptomyces olivaceoviridis chitinase in comparison with its proteolytically processed form. Eur. J. Biochem. 229(1): 132-139. DOI: 10.1111/j.14321033.1995.tb20447.x.

Bork P and Doolittle RF (1992). Proposed acquisition of an animal protein domain by bacteria. Proc. Natl. Acad. Sci. U $S$ A. 89(19): 8990-8994. DOI: 10.1073/pnas.89.19.8990.

Busby JN, Landsberg MJ, Simpson RM, Jones SA, et al. (2012). Structural analysis of Chi1 Chitinase from Yen-Tc: the multisubunit insecticidal ABC toxin complex of Yersinia entomophaga.J. Mol. Biol. 415(2): 359-371. DOI: 10.1016/j.jmb.2011.11.018.

Chang YM, Chen LC, Wang HY, Chiang CL, et al. (2014) Characterization of an Acidic Chitinase from Seeds of Black Soybean (Glycine $\max (\mathrm{L})$ Merr Tainan No. 3). PLoS one. 9(12): e113596. DOI: 10.1371/journal.pone0113596.

De S, Kaur G, Roy A, Dogra G, et al. (2010). A Simple Method for the Efficient Isolation of Genomic DNA from Lactobacilli Isolated from Traditional Indian Fermented Milk (dahi). Indian J. Microbiol. 50(4): 412-418. DOI: 10.1007/s12088-011-0079-4.

Dong X, Zhao Y, Ran X, Guo L, et al. (2017). Overexpression of a New Chitinase Gene EuCHIT2 Enhances Resistance to Erysiphe cichoracearum DC in Tobacco Plants. Int. J. Mol. Sci. 18(11): 2361. DOI: 10.3390/ijms18112361.

Greń I, Wojcieszyńska D, Guzik U, Perkosz M, et al. (2010). Enhanced biotransformation of mononitrophenols by Stenotrophomonas maltophilia KB2 in the presence of aromatic compounds of plant origin. World J. Microbiol. Biotechnol. 26: 289-295. DOI: 10.1007/s11274-009-0172-6.

Hamid R, Khan MA, Ahmad M, Ahmad MM, et al. (2013). Chitinases an update. J. Pharm. Bioallied Sci. 5(1): 21-9. DOI: $10.4103 / 0975-7406.106559$.

Honda S, Kunii T, Nohara K, Wakita S, et al. (2017). Characterization of a Bacillus thuringiensis chitinase that binds to cellulose and chitin. AMB Express. 7(1): 51. DOI: 10.1186/s13568-017-0352-y.

Kobayashi DY, Reedy RM, Bick J and Oudemans PV (2002). Characterization of a chitinase gene from Stenotrophomonas maltophilia strain $34 \mathrm{~S} 1$ and its involvement in biological control. Appl Environ. Microbiol. 68(3): 1047-1054. DOI.org/10.1128/aem.68.3.1047-1054.2002.

Chan KG, Chong TM, Adrian TG, Kher HL, et al. (2015). Whole-Genome Sequence of Stenotrophomonas maltophilia ZBG7B Reveals Its Biotechnological Potential. Genome Announc. 3(6): e01442-15. DOI: 10.1128/genomeA.01442-15.

Kumar S, Stecher G and Tamura K (2016). MEGA7: Molecular Evolutionary Genetics Analysis Version 7.0 for Bigger Datasets. Mol. Biol. Evol. 33(7): 1870-1874. DOI: 10.1093/molbev/msw054.

Laribi-Habchi H, Bouanane-Darenfed A, Drouiche N, Pauss A, et al. (2015). Purification, characterization, and molecular cloning of an extracellular chitinase from Bacillus licheniformis stain LHH100 isolated from wastewater samples in Algeria. Int. J. Biol. Macromol. 72: 1117-1128. DOI: 10.1016/j.ijbiomac.2014.10.035.

$\mathrm{Li} \mathrm{H}$ and Greene LH (2010). Sequence and structural analysis of the chitinase insertion domain reveals two conserved motifs involved in chitin-binding. PLoS One. 5(1): e8654. DOI: 10.1371/journal.pone.0008654.

Malecki PH, Vorgias CE, Petoukhov MV, Svergun DI, et al. (2014). Crystal structures of substrate-bound chitinase from the psychrophilic bacterium Moritella marina and its structure in solution. Acta Crystallogr D. Biol. Crystallogr. 70(Pt 3): 676-684. DOI: 10.1107/S1399004713032264.

Metcalfe AC, Krsek M, Gooday GW, Prosser JI, et al. (2002). Molecular analysis of a bacterial chitinolytic community in an upland pasture. Appl. Environ. Microbiol. 68(10): 5042-5050. Doi: 10.1128/aem.68.10.5042-5050.2002.

Oyeleye A and Normi YM (2018). Chitinase: diversity, limitations, and trends in engineering for suitable applications. Biosci. Rep. 29. 38(4): BSR2018032300. DOI: 10.1042/BSR20180323.

Perera L, Russell JR, Provan J and Powell W (2000). Use of microsatellite DNA markers to investigate the level of genetic diversity and population genetic structure of coconut (Cocos nucifera L.). Genome. 43(1): 15-21. DOI: $10.1139 / \mathrm{g} 99-079$.

Rathore AS and Gupta RD (2015). Chitinases from Bacteria to Human: Properties, Applications, and Future Perspectives. Enzyme Res. 2015: 791907. DOI: 10.1155/2015/791907. 
Salas-Ovilla R, Gálvez-López D, Vázquez-Ovando A, Salvador-Figueroa M, et al. (2019). Isolation and identification of marine strains of Stenotrophomona maltophilia with high chitinolytic activity. PeerJ. 3. 7: e6102. DOI: 10.7717/peerj.6102.

Sanger F, Nicklen S and Coulson AR (1977). DNA sequencing with chain-terminating inhibitors. Proc. Natl. Acad. Sci. US A. 74(12): 5463-7. DOI: 10.1073/pnas.74.12.5463.

Shah R, Ohashi T, Erickson HP and Oas TG. (2017). Spontaneous Unfolding-Refolding of Fibronectin Type III Domains Assayed by Thiol Exchange: Thermodynamic stability correlates with rates of unfolding rather than folding. J. Biol. Chem. 292(3): 955-966. DOI: 10.1074/jbc.M116.760371.

Shiro M, Ueda M, Kawaguchi T and Arai M (1996). Cloning of a cluster of chitinase genes from Aeromonas sp. No. 10S-24. Biochim. Biophys Acta. 1305(1-2): 44-8. DOI: 10.1016/0167-4781(95)00213-8.

Sitrit Y, Vorgias CE, Chet I and Oppenheim AB (1995). Cloning and primary structure of the chiA gene from Aeromonas caviae. J. Bacteriol. 177(14): 4187-9. DOI: 10.1128/jb.177.14.4187-4189.1995.

Suckstorff I and Berg G (2003). Evidence for dose-dependent effects on plant growth by Stenotrophomonas strains from different origins. J. Appl. Microbiol. 95(4): 656-63. DOI: 10.1046/j.1365-2672.2003.02021.x.

Tan WS, Yin WF and Chan KG (2015). Insights into the Quorum-Sensing Activity in Aeromonas hydrophila Strain M013 as Revealed by Whole-Genome Sequencing. Genome Announc. 3(1): e01372-14. DOI: 10.1128/genomeA.01372-14.

Tsujibo H, Orikoshi H, Tanno H, Fujimoto K, et al. (1993). Cloning, sequence, and expression of a chitinase gene from a marine bacterium, Altermonas sp. strain O-7. J. Bacteriol. 175(1): 176-81. DOI: 10.1128/jb.175.1.176-181.1993.

Uchiyama T, Katouno F, Nikaidou N, Nonaka T, et al. (2001). Roles of the exposed aromatic residues in crystalline chitin hydrolysis by chitinase A from Serratia marcescens 2170. J. Biol. Chem. 276(44): 41343-9. DOI: 10.1074/jbc.M103610200.

Vaaje-Kolstad G, Horn SJ, Sørlie M and Eijsink VG. (2013). The chitinolytic machinery of Serratia marcescens a model system for enzymatic degradation of recalcitrant polysaccharides. FEBS J. 280(13): 3028-49. doi: 10.1111/febs.12181.

Viterbo A, Haran S, Friesem D, Ramot O, et al. (2001). Antifungal activity of a novel endochitinase gene (chit36) from Trichoderma harzianum Rifai TM. FEMS Microbiol Lett. 200(2): 169-74. DOI: 10.1111/j.15746968.2001.tb10710.x.

West P and Colwell RR (1984). Identification and classification of Vibrionaceae: An overview. In: Vibrios in the environment. (Colwell RR, ed). John Wiley and Sons, New York. pp: 285-363.

Yuli PE, Suhartono MT, Rukayadi Y, Hwang JK, et al. (2004) Characteristics of thermostable chitinase enzymes from the Indonesian Bacillus sp.13.26. Enzyme Microb. Technol. 35(2): 147-153. DOI: 10.1016/j.enzmictec.2004.03.017.

Zhong W, Ding S and Guo H (2015). The chitinase C gene PsChiC from Pseudomonas sp. and its synergistic effects on larvicidal activity. Genet. Mol. Biol. 38(3): 366-72. DOI: 10.1590/S1415-475738320140320. 